\title{
Tumor-infiltrating $\gamma \delta$ T Iymphocytes: pathogenic role, clinical significance, and differential programing in the tumor microenvironment
}

\author{
Elena Lo Presti ${ }^{1,2}$, Franceso Dieli ${ }^{1,2}{ }^{*}$ and Serena Meraviglia ${ }^{1,2}$ \\ ${ }^{1}$ Dipartimento di Biopatologia e Metodologie Biomediche, University of Palermo, Palermo, Italy \\ ${ }^{2}$ Central Laboratory of Advanced Diagnosis and Biomedical Research (CLADIBIOR), University of Palermo, Palermo, Italy
}

\section{Edited by:}

Julie Dechanet-Merville, Centre

National de la Recherche Scientifique (CNRS), France

\section{Reviewed by:}

Daniel Olive, INSERM UMR 891 Institut Paoli Calmettes, France

Emmanuel Scotet, Institut National de la Santé et de la Recherche Médicale, France

\section{*Correspondence:}

Franceso Dieli, Central Laboratory for Advanced Diagnostic and Biomedical Research (CLADIBIOR), Università di Palermo, Corso Tukory 211, Palermo 90134, Italy

e-mail:francesco.dieli@unipa.it
There is increasing clinical evidence indicating that the immune system may either promote or inhibit tumor progression. Several studies have demonstrated that tumors undergoing remission are largely infiltrated by $T$ lymphocytes [tumor-infiltrating lymphocytes (TILs)], but on the other hand, several studies have shown that tumors may be infiltrated by TILs endowed with suppressive features, suggesting that TILs are rather associated with tumor progression and unfavorable prognosis. $\gamma \delta T$ lymphocytes are an important component of TILs that may contribute to tumor immunosurveillance, as also suggested by promising reports from several small phase-I clinical trials. Typically, $\gamma \delta$ T lymphocytes perform effector functions involved in anti-tumor immune responses (cytotoxicity, production of IFN- $\gamma$ and TNF- $\alpha$, and dendritic cell maturation), but under appropriate conditions they may divert from the typical Th1-like phenotype and polarize to Th2, Th17, and Treg cells thus acquiring the capability to inhibit anti-tumor immune responses and promote tumor growth. Recent studies have shown a high frequency of $\gamma \delta T$ lymphocytes infiltrating different types of cancer, but the nature of this association and the exact mechanisms underlying it remain uncertain and whether or not the presence of tumor-infiltrating $\gamma \delta$ T lymphocytes is a definite prognostic factor remains controversial. In this paper, we will review studies of tumor-infiltrating $\gamma \delta T$ lymphocytes from patients with different types of cancer, and we will discuss their clinical relevance. Moreover, we will also discuss on the complex interplay between cancer, tumor stroma, and $\gamma \delta T$ lymphocytes as a major determinant of the final outcome of the $\gamma \delta$ T lymphocyte response. Finally, we propose that targeting $\gamma \delta$ T lymphocyte polarization and skewing their phenotype to adapt to the microenvironment might hold great promise for the treatment of cancer.

Keywords: $\gamma \delta$ T cells, TIL, IL-17, immunosuppression, tumor microenvironment

\section{$\gamma \delta$ T LYMPHOCYTES: ANTIGEN RECOGNITION AND EFFECTOR FUNCTIONS}

T cells carrying the $\gamma \delta$ T cell receptor (TCR) are important effector cells that may play a role in the anti-tumor immune response. $\gamma \delta$ Cells are not a homogeneous population of cells with a single physiological role. Instead, ever increasing complexity in both phenotype and function is being ascribed to $\gamma \delta$ cell subsets from various tissues and locations, both in mice and humans.

$\gamma \delta \mathrm{T}$ cells account for $1-5 \%$ of $\mathrm{CD}^{+} \mathrm{T}$ cells in the peripheral blood, but constitute a major subset in other anatomic sites, such as the intestine or the skin [here, however, only in the murine but not in human skin (1)]. In the blood of most healthy individuals, $\mathrm{T}$ cells expressing the $\mathrm{V} \delta 2$ gene paired with one particular $\mathrm{V} \gamma 9$ chain (referred to as $\mathrm{V} \gamma 9 \mathrm{~V} \delta 2 \mathrm{~T}$ cells) account for 50 to $>90 \%$ of the $\gamma \delta \mathrm{T}$ cell population. In contrast, intestinal intraepithelial $\gamma \delta$ $\mathrm{T}$ cells frequently express the $\mathrm{V} \delta 1$ gene, which can associate with different $\mathrm{V} \gamma$ elements $(1,2) . \mathrm{V} \delta 1 \gamma \delta \mathrm{T}$ cells recognize the MHC class I-related molecules MICA, MICB, and ULBPs, which are expressed on epithelial cells by heat shock or oxidative stress and are constitutively expressed to variable levels on many epithelial and hematopoietic tumor cells $(3,4)$. It has been debated whether MICA/MICB and ULBPs are directly recognized by the V $\delta 1$ TCR or, indirectly activate $\mathrm{V} \delta 1 \mathrm{~T}$ cells upon binding to the stimulatory natural killer (NK) receptor, NKG2D, which is also expressed by the vast majority of $\gamma \delta$ T cells.

V $\gamma 9 \mathrm{~V} 82 \mathrm{~T}$ cells recognize phosphoantigens (PAgs) without requirement for antigen processing and presentation, and MHC restriction. PAgs are pyrophosphates derived from the microbial non-mevalonate isoprenoid biosynthesis pathway $(5,6)$. Structurally related pyrophosphates are generated in eukaryotic cells through the mevalonate pathway. Micromolar concentrations of endogenous pyrophosphates are required for $\mathrm{V} \gamma 9 \mathrm{~V} \delta 2 \mathrm{~T}$ cell activation and such concentrations are achieved after cellular stress and transformation (7). Given the cross-reactivity between microbial and self PAgs, there is a great interest in elucidating how TCR signaling can be induced by such small molecules. PAgs can directly activate $\mathrm{V} \gamma 9 \mathrm{~V} \delta 2 \mathrm{~T}$ cells, but such activation is greatly enhanced by monocytes and/or dendritic cells (DCs). Hence, either PAgs 
are presented as cargo to the reactive $\gamma \delta$ TCR or their cellular processing somehow sensitizes cell recognition through the engagement of the V $\gamma 9 \mathrm{~V} \delta 2$ TCR by stabilizing surface expression of a TCR-binding molecules (8). A candidate molecule involved in intracellular PAg processing is the F1-ATPase, which directly binds the V $\gamma 9 \mathrm{~V} \delta 2$ TCR and interacts with ApppI, an adenosine derivative of IPP (9). Moreover, it has been recently found that PAg-induced $\mathrm{V} \gamma 9 \mathrm{~V} \delta 2 \mathrm{~T}$ cell activation requires butyrophilin 3A1 (BTN3A1) (10-12). Therefore, production of exogenous PAgs or up-regulation of endogenous PAgs in human cells in response to either infections or tumor transformation provokes $\mathrm{V} \gamma 9 \mathrm{~V} \delta 2 \mathrm{~T}$ cell reactivity, albeit at substantially different sensitivity.

Intracellular levels of PAgs can be manipulated by drugs. Aminobisphosphonates, such as zoledronic acid, which are in clinical use for the treatment of osteoporosis and bone metastasis, are potent inhibitors of the downstream enzyme of the mevalonate pathway farnesyl pyrophosphate synthase, thereby leading to the intracellular accumulation of upstream metabolites as IPP and in consequence to $\mathrm{V} \gamma 9 \mathrm{~V} \delta 2 \mathrm{~T}$ cell activation $(13,14)$. On the contrary, statins block the upstream enzyme hydroxymethylglutaryl-CoA reductase and inhibits IPP production, inhibiting V $\gamma 9 \mathrm{~V} \delta 2 \mathrm{~T}$ cell activation (15).

V $\gamma 9 \mathrm{~V} 82 \mathrm{~T}$ cells express numerous molecules potentially associated with different stages of differentiation, migration, and functions. V $\gamma 9 \mathrm{~V} \delta 2 \mathrm{~T}$ cells include "naive" and "central memory" phe-

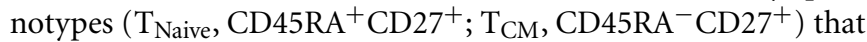
home to secondary lymphoid organs, but lack immediate effector function, and "effector/memory" ( $\left.\mathrm{T}_{\mathrm{EM}}, \mathrm{CD} 4 \mathrm{RA}^{-} \mathrm{CD} 27^{-}\right)$ and "terminally differentiated" ( $\left.\mathrm{T}_{\mathrm{EMRA}}, \mathrm{CD} 45 \mathrm{RA}^{+} \mathrm{CD} 27^{-}\right)$phenotypes that home to sites of inflammation and display immediate effector function (16).

While $\mathrm{T}_{\text {Naive }}$ and $\mathrm{T}_{\mathrm{CM}}$ cells readily respond to PAgs stimulation, $\mathrm{T}$ cells with effector memory ( $\mathrm{T}_{\mathrm{EM}}$ ) and terminally differentiated effector memory ( $\mathrm{T}_{\mathrm{EMRA}}$ ) expand in response to homeostatic cytokines as IL-15 (17) and differentiate in the presence of polarizing cytokines (18). On activation, $\mathrm{V} \gamma 9 \mathrm{~V} \delta 2$ cells can be skewed toward distinct effector functions depending on polarizing cytokines, in analogy to CD4 helper T cells. Typically, human $\mathrm{V} \gamma 9 \mathrm{~V} \delta 2 \mathrm{~T}$ cells default toward type 1 cytokine production $(\gamma \delta 1)$, but under appropriate culture conditions they divert from the typical $\gamma \delta 1$ phenotype and polarize to $\gamma \delta 2(19,20), \gamma \delta 17(21-23), \gamma \delta_{\mathrm{FH}}$ $(24,25)$, and $\gamma \delta$ reg cells $(26)$. Such a broad plasticity emphasizes the capacity of $\mathrm{V} \gamma 9 \mathrm{~V} \delta 2 \mathrm{~T}$ cells to influence the nature of immune response to different challenges.

\section{$\gamma \delta$ T CELLS FOR TUMOR IMMUNOTHERAPY}

The major goal of tumor immunotherapy is the induction of adaptive responses of B cells and MHC-restricted $\alpha \beta$ T cells, particularly CD8 cytotoxic T cells. Nonetheless, despite major advances in this area, durable responses are rare and immunotherapy is not yet an established modality to treat tumors. Furthermore, tumors frequently develop strategies to escape immune responses $(27,28)$. In contrast to $\alpha \beta \mathrm{T}$ cells, $\gamma \delta \mathrm{T}$ cells have unique features (see Table 1), which makes them good candidates for effective tumor immunotherapy. For instance, they lack MHC restriction, and do not require co-stimulation. Therefore, common tumor antigens without MHC restriction provide broader applicability of $\gamma \delta \mathrm{T}$

\section{Table 1 | Advantages of using $\gamma \delta$ T cells for tumor immunotherapy.}

The frequency of $\gamma \delta$ T cells is very high $\left(1-5 / 10^{2}\right)$, compared to that of Ag-specific $\alpha \beta$ T cells $\left(1 / 10^{5}-10^{6}\right)$

$\gamma \delta$ T cells can recognize and lyse a broad range of tumor cells and there is no need to target tumor-specific Ags

$\gamma \delta \mathrm{T}$ cells lack $\mathrm{MHC}$ restriction in antigen recognition

$\gamma \delta T$ cell activation does not require co-stimulatory signals (e.g., CD28)

$\mathrm{mAb}$ can be used in vivo to enhance $\gamma \delta \mathrm{T}$ cell cytotoxicity (ADCC)

$\gamma \delta$ T cells seem to be devoid of GVH activity

FDA-approved drugs (Zoledronate, IL-2) available for $\gamma \delta$ T cell expansion in vivo

Large scale ex vivo expansion of $\gamma \delta$ T cells and clinical grade sets for purification

cells across a wide range of tumors and patients with diverse $\mathrm{MHC}$ alleles. Moreover, $\gamma \delta \mathrm{T}$ cells display potent cytotoxic and antitumor activity in vitro (29-33) and in xenograft models in vivo $(34,35)$. Cytotoxicity of $\gamma \delta \mathrm{T}$ cells against tumor cells is associated with increased production of PAgs (36), which is, at least, partly due to the increased expression of hydroxymethylglutaryl-CoA reductase, the rate limiting enzyme of the mevalonate pathway (36). Moreover, intracellular levels of IPP can be manipulated by aminobisphosphonates (13-15, 37-39), thereby leading to the intracellular accumulation of IPP and in consequence to activation of $\mathrm{V} \gamma 9 \mathrm{~V} \delta 2 \mathrm{~T}$ cells (36). As above discussed, in addition to the binding of the antigenic molecules to the reactive TCR, V $\gamma 9 \mathrm{~V} \delta 2 \mathrm{~T}$ cells express NK cell activating receptors such as NKG2D, which recognizes target cells expressing MICA, MICB, and ULBPs (3, 4, $40,41)$. These interactions may prove crucial in $\mathrm{V} \gamma 9 \mathrm{~V} \delta 2 \mathrm{~T}$ cell recognition and killing of tumors of hematopoietic origin. In fact, the expression levels of ULBP1 determine lymphoma susceptibility to $\mathrm{V} \gamma 9 \mathrm{~V} \delta 2 \mathrm{~T}$ cell-mediated cytolysis, highlighting a thus far unique physiologic relevance for tumor recognition by $\mathrm{V} \gamma 9 \mathrm{~V} \delta 2 \mathrm{~T}$ cells $(42,43)$.

After recognizing target cells via the TCR, or NKG2D, or both, V $\gamma 9$ V $\delta 2 \mathrm{~T}$ cells preferentially use the perforin/granzyme (44) and/or TRAIL (45) pathways, as well as the Fas/FasL killing signal (46), for cytotoxicity against target cells like tumor cells. In addition, activated $\mathrm{V} \gamma 9 \mathrm{~V} \delta 2 \mathrm{~T}$ cells secrete IFN- $\gamma$ and TNF- $\alpha$, which have cytotoxic activity against tumor cells directly and indirectly via stimulating macrophages and DCs (47-49).

Overall, the potent anti-tumor activity of $\mathrm{V} \gamma 9 \mathrm{~V} \delta 2 \mathrm{~T}$ cells and their wide reactivity to several tumor cell types has led to the exploration of their therapeutic potential. Two strategies have been developed to apply the anti-tumor activities of $\mathrm{V} \gamma 9 \mathrm{~V} \delta 2 \mathrm{~T}$ cells to cancer immunotherapy: (1) in vivo administration of compounds that activate $\mathrm{V} \gamma 9 \mathrm{~V} \delta 2 \mathrm{~T}$ cells and (2) adoptive transfer of ex vivoexpanded $\mathrm{V} \gamma 9 \mathrm{~V} \delta 2 \mathrm{~T}$ cells. Several small-sized clinical trials have tested the efficacy of any of these two strategies in patients with various tumor types and a recent meta-analysis based on data from 13 clinical trials including a total of 204 patients has demonstrated that $\mathrm{V} \gamma 9 \mathrm{~V} \delta 2 \mathrm{~T}$ cell-based immunotherapy improves overall survival and, in view of its low toxicity grade (50), provides a proof of principle for its utilization as adjuvant to conventional therapies. 
TUMOR-INFILTRATING $\gamma \delta$ T CELLS AND THEIR CORRELATION TO CANCER OUTCOME

Tumor-infiltrating leukocytes are an heterogeneous population of immune cells that have been found in a wide variety of solid tumors (51) and the extent of leukocyte infiltration has been often associated with improved prognosis (52). However, there is a limited number of studies regarding the contribution of individual leukocyte subsets to survival. Tumor-infiltrating leukocytes include cells of the myeloid lineage (granulocytes, macrophages, and myeloid-derived suppressor cells) and several different lymphocyte subsets (T, B, and NK), each with different impact on tumor progression. Results of mouse tumor models and human cohort studies have suggested that any individual leukocyte population may correlate with poor or better prognostic factors, such as tumor stage/grade, presence of metastasis, and diseasefree/overall survival. In general, infiltration by myeloid cells has been associated with tumor progression, while the presence of abundant $\mathrm{T}$ cells (particularly of the $\mathrm{CD} 8$ subset) is associated with tumor regression and improved prognosis. However, the limits of the immunohistochemical techniques largely used in retrospective clinical studies, have so far prevented a detailed descriptions of different tumor-infiltrating leukocyte populations as well as evaluation of their functional properties in the tumor microenvironment. For instance, tumor-infiltrating $\mathrm{T}$ lymphocytes may be endowed with regulatory function and hence promote tumor progression.

Several studies have shown that $\gamma \delta \mathrm{T}$ cells are present among tumor-infiltrating lymphocytes (TILs) from patients affected by different types of cancer, but their clinical relevance remains still obscure because of conflicting results obtained.

In detail, there have been five relatively recent large studies, which have correlated tumor-infiltrating $\gamma \delta \mathrm{T}$ cells with several different clinical features:

Bialasiewicz et al. (53) evaluated by immunohistochemical analysis TILs in 113 specimens from patients with necrotizing choroidal melanoma. They detected TILs in $76 \%$ of samples and $\gamma \delta \mathrm{T}$ cells, mainly of the $\mathrm{V} \delta 1$ subset were present in $52 \%$ of samples. Most notably, the presence of $\gamma \delta \mathrm{T}$ cells in tumors positively correlated with patient's survival, indicating that tumor-infiltrating $\gamma \delta \mathrm{T}$ cells are a prognostically favorable factor.

Inman et al. (54) assessed by immunohistochemical analysis total $\gamma \delta \mathrm{T}$ cells in 248 renal cancer specimens and correlated these values with clinicopathologic prognostic factors and cancer outcome. They found that percentages of intratumoral $\gamma \delta \mathrm{T}$ cells were usually very low ( $<1 \%$ of the $\mathrm{CD} 3^{+}$population) in nearly all tested tumor specimens and did not correlate with any examined prognostic factor or even with survival. Authors concluded that the role of $\gamma \delta \mathrm{T}$ cells in renal cancer is questionable.

Ma et al. (55) examined by immunohistochemistry total $\gamma \delta \mathrm{T}$ cells infiltrating breast cancer in specimens of 46 patients. $\gamma \delta \mathrm{T}$ cells were detected in nearly all cancer patients (93\%), but only in $3 \%$ of normal breast specimen. Authors did not quantify the percentages of intratumoral $\gamma \delta \mathrm{T}$ cells, but when an arbitrary cut-off of nine $\gamma \delta \mathrm{T}$ cells per high magnification microscopic field was used to define TIL-high $(>9)$ and TIL-low $(<9)$ groups, authors found that $\gamma \delta \mathrm{T}$ cell numbers were positively correlated with advanced tumor stages, HER2 expression status, and high lymph node metastasis, but inversely correlated with relapse-free survival and overall survival of patients. Multivariate and univariate analysis of tumor-infiltrating $\gamma \delta \mathrm{T}$ cells and other prognostic factors further suggested that intratumoral $\gamma \delta \mathrm{T}$ cells represented the most significant independent prognostic factor for assessing severity of breast cancer compared with the other known factors. Authors concluded that tumor-infiltrating $\gamma \delta \mathrm{T}$ cells play a crucial role in breast cancer progression and pathogenesis and may serve as a valuable and independent prognostic biomarker for human breast cancer.

Cordova et al. (56) studied the representation of tumorinfiltrating $\gamma \delta \mathrm{T}$ cells from 74 patients with primary melanoma. $\gamma \delta \mathrm{T}$ cells were the major subset among $\mathrm{CD}^{+} \mathrm{T}$ lymphocytes and comprised equal percentages of $\mathrm{V} \delta 1$ and $\mathrm{V} \delta 2 \mathrm{~T}_{\mathrm{EM}}$ or $\mathrm{T}_{\mathrm{EMRA}}$ phenotypes. In this study, the presence of $\gamma \delta \mathrm{T}$ cells, and in particular the V $\delta 2$ subset, among TILs significantly correlated with early stage melanoma, while percentages of infiltrating $\mathrm{V} \delta 1 \mathrm{~T}$ cells did not correlate with any examined prognostic factor of melanoma.

Finally, Wu et al. (57) demonstrated that $\gamma \delta \mathrm{T}$ cells $(\gamma \delta 17)$ are the major source of IL-17 in human colon cancer, with the majority $(80 \%)$ of the IL- $17^{+} \gamma \delta \mathrm{T}$ cells expressing $\mathrm{V} \delta 1$ and $20 \%$ expressing V82. Importantly, analyzing 117 colon cancer samples, authors found that $\gamma \delta 17$ cell infiltration positively correlated with tumor stages and other clinicopathological factors (tumor size, tumor invasion, lymphatic and vascular invasion, lymph node metastasis, and serum CEA levels), indicating that tumor-infiltrating $\gamma \delta 17$ $\mathrm{T}$ cells are associated with tumor invasiveness and progression and may thus represent a prognostic factor in human colon cancer.

\section{TUMOR-INFILTRATING $\gamma \delta$ T CELLS: WHAT ARE THEY AND WHAT DO THEY DO ?}

The above discussed findings that tumor-infiltrating $\gamma \delta$ T cells correlate with tumor remission, or with tumor progression or even fail to correlate with any prognostic feature strongly suggest that $\gamma \delta \mathrm{T}$ cells in the tumor microenvironment may play substantially different functions; hence positive or negative correlation with prognosis may depend on the specific $\gamma \delta \mathrm{T}$ cell subset/function recruited at the tumor site. Furthermore, the net biologic effects of $\gamma \delta \mathrm{T}$ cells may depend on the tumor type and the tumor site, perhaps reflecting microenvironmental differences: for instance TGF- $\beta$, which is abundantly secreted at the tumor site by tumorinfiltrating macrophages or by tumor cells themselves, may favor the differentiation of $\gamma \delta$ cells with Treg-like properties, which in turn inhibit anti-tumor immune responses.

Initial studies on the functional properties of tumor-infiltrating $\gamma \delta \mathrm{T}$ cells were performed using polyclonal $\gamma \delta \mathrm{T}$ cell lines generated in vitro upon long term culture with mitogen/antigen and IL-2: this approach was mainly due to the very low number of $\gamma \delta \mathrm{T}$ cells recovered from tumor specimen and to the lack of suitable techniques, which allowed precise detection of functional markers. These studies have unequivocally demonstrated that $e x$ vivo-expanded $\gamma \delta \mathrm{T}$ cell lines and clones from renal, breast, lung, ovary, colon, and pancreatic cancer efficiently kill stabilized tumor cell lines and freshly isolated tumor cells and generally $\mathrm{V} \delta 1 \mathrm{~T}$ cell lines had the higher cytotoxic activity compared to $\mathrm{V} \delta 2 \mathrm{~T}$ cell lines (58-63). Accordingly, Cordova et al. (56) confirmed these results using polyclonal $\gamma \delta \mathrm{T}$ cell lines derived from melanoma; 
both $\mathrm{V} \delta 1$ and $\mathrm{V} \delta 2 \mathrm{~T}$ cell lines produced equal amounts of TNF- $\alpha$ and IFN- $\gamma$, but while the majority $(75 \%)$ of $V \delta 1 \mathrm{~T}$ cell lines exerted potent cytotoxic activity against melanoma cell line in vitro, only $25 \%$ of the V $\delta 2 \mathrm{~T}$ cell lines showed appreciable lytic activity. Therefore, based on their cytolytic activity and production of cytokines with proven anti-tumor effect, tumor-infiltrating $\gamma \delta \mathrm{T}$ cells have been long regarded as important players of the antitumor immune response. However, both the failure to consistently detect a positive correlation between the presence of $\gamma \delta$ T cells in the tumor microenvironment and the patient's prognosis, as well as the improvement of immunological techniques to detect functional signatures even in very small tissue samples have subverted the concept that $\gamma \delta \mathrm{T}$ cells are simply an important component of resistance to cancer and suggested that their function may be extremely pleiotropic and including either effector or suppressive potential.

In 2007, Peng and colleagues (64) unexpectedly identified a $\mathrm{V} \delta 1^{+}$population (which comprised over $95 \%$ of the total $\gamma \delta$ T cells population) among breast cancer-infiltrating lymphocytes capable to suppress immune responses. In particular, $\mathrm{V} \delta 1$ cells inhibited CD4 and CD8 T cell activation and impaired DC maturation and function. Although the mechanisms responsible for the regulatory activity of tumor-infiltrating V $\delta 1$ cells was not investigated in that paper, it seems to involve TLR8 signaling pathway, as suppression was reversed by TLR8 ligands. Later on, the same group reported (65) that breast cancer-infiltrating V $\delta 1$ cells induced both $\mathrm{T}$ cell and DC senescence and the senescent T cells and DCs in turn became regulatory cells, thus determining amplification of the immunosuppressive process. Interestingly, and surprisingly, accumulation of regulatory $\mathrm{V} \delta 1$ cells in the context of breast cancer (where they account for approximately $30 \%$ of the total lymphocyte population) is not due to proliferation of resident $V \delta 1$ cells but to their recruitment mediated by IP-10 secreted by breast cancer cells.

In addition to the above quoted studies on tumor-infiltrating human regulatory $\gamma \delta \mathrm{T}$ cells, four recent reports, three in mice and one in humans, have shed light on the regulatory role played by IL-17-producing $\gamma \delta$ T cells $(\gamma \delta 17)$ and have also defined the underlying mechanisms.

Using a transplantable tumor mouse model, Wakita et al. (66) observed that $\gamma \delta$ T cells accounted for $25 \%$ of all TILs and selectively produced IL-17 but not IFN- $\gamma$. Importantly, absence of IL-17 caused inhibition of tumor growth, which correlated with a reduced number of blood vessels within the tumor and reduced expression levels of VEGF and Ang-2 in tumor cells. This indicates that tumor-infiltrating $\gamma \delta 17 \mathrm{~T}$ cells promote angiogenesis, and thus tumor growth.

A similar detrimental effect of IL-17 has been reported by Ma and colleagues (67) in an hepatocellular carcinoma mouse model. Similarly to the findings of Wakita et al., $\gamma \delta$ T cells were the major source of IL-17 amongst lymphocytes infiltrating hepatocellular carcinoma. In this model, absence of IL-17 reduced tumor growth, while its administration promoted the growth of hepatocellular carcinoma. However, the mechanism responsible for the anti-tumor activity of IL-17 was different from that reported by Wakita and involved a reciprocal activatory interaction between the $\gamma \delta 17$ cells and MDSC, which was mediated by cancer cells: in detail, $\gamma \delta \mathrm{T}$ cell-derived IL-17 induced CXCL5 production by tumor cells, which in turn recruited MDSC to the tumor sites via CXCL5/CXCR2-interaction. Once at the tumor site, IL-17 induced production of IL-1 $\beta$ and IL-23 in MDSC, which amplify differentiation of $\gamma \delta 17$ cells. This positive feedback between $\gamma \delta 17$ cells and MDSC sustains immunosuppression and promotes tumor growth.

The third mouse study by Silva Santos and colleagues (68) used a transplantable peritoneal/ovarian cancer, and confirmed the crucial role of $\gamma \delta 17$ in promoting cancer growth. $\gamma \delta 17$ accumulated in the peritoneal cavity and were the main source of IL-17 also in this model. $\gamma \delta 17$ caused the recruitment at the tumor site of an unconventional population of small macrophages that expressed IL-17 receptor and a number of pro-tumor and pro-angiogenic molecules amongst which VEGF and TGF- $\beta$, which promoted cancer cell proliferation and tumor growth.

The fourth study on the participation of $\gamma \delta 17$ cells in cancer was performed by $\mathrm{Wu}$ et al. (57) in human colorectal cancer. In that study, tumor-infiltrating $\gamma \delta$ T cell was the main source of IL-17 and $80 \%$ of the $\gamma \delta 17$ cells expressed $V \delta 1$. Of note however, $\gamma \delta 17$ constituted approximately $25 \%$ of all tumor-infiltrating V $\delta 1$ cells and co-produced TNF- $\alpha$, IL-8, and GM-CSF. All these cytokines, in different combinations, caused recruitment (IL-8 and GM-CSF) and survival, activation, and proliferation (TNF- $\alpha$, IL- 8 , and IL-17) of MDSC that in turn mediate immunosuppression and promote tumor growth.

Altogether these results clearly demonstrate that $\gamma \delta 17$ cells are key mediators of tumor-associated immunosuppression thereby influencing tumor progression.

\section{HYPOTHESIS: TUMOR MICROENVIRONMENT AS THE CRITICAL DETERMINANT OF TUMOR-INFILTRATING $\gamma \delta$ T CELL FATE}

The conditions under which $\gamma \delta \mathrm{T}$ cells can contribute to tumor control versus immune suppression need to be defined. There are several theoretical possibilities to answer the fundamental question of the molecular mechanisms that explain these two $\gamma \delta$ T cell phenotypes.

First, it is possible that genetic differences in tumor cells influence the host response, through the involvement of different pathways that are mutated or activated in a heterogeneous fashion and that regulate the expression of immune system regulatory genes. For instance, tumor cells with STAT3 activation show impaired production of chemokines and cytokines, but increased production of immunosuppressive factors and thus escape immune recognition (69).

Second, it is possible that polymorphism of regulatory genes might influence lymphocyte activation at the tumor site. For instance, IRF5 polymorphism is associated with clinical response to adoptively transferred TILs in melanoma patients (70).

Third, it is likely that exposure to certain pathogens or even the intestinal microbiome could change the frequency, phenotype, and functions of TILs. For instance, Wu et al. (57) showed that in colon cancer patients, destruction of the epithelial barrier caused by tumor development results in tumor invasion by commensal bacteria (E. coli) and release of bacterial product, which promote IL-23 production by DCs and $\gamma \delta 17$ cell polarization in situ. 
Fourth, it is likely (and this is the possibility we favor) that tumor microenvironment plays a key role. By definition, tumor microenvironment is a complex network of different cell types, soluble factors, signaling molecules, and extracellular matrix components, which orchestrate the fate of tumor progression (71). In fact, in addition to the tumor cells and to the several lymphoid and myeloid cell types that infiltrate tumors, classical cellular components of the solid tumor stromal microenvironment also influence the host immune response. The tumor stroma consists of fibroblasts, macrophages, and vascular endothelial cells, with variable amounts of extracellular matrix, all of which contribute not only as a support structure for tumor growth, but can also impair host immune responses and likely contribute to the quality of immune cell infiltration (71). We hypothesize (Figure 1) that, at early stages of tumor development $\gamma \delta$ T cells of the $\gamma \delta 1$ type producing cytokines with proven anti-tumor activity (IFN- $\gamma$ and TNF- $\alpha$ ) and equipped with cytotoxic potential either expand locally (V $\delta 1)$ or are recruited at the tumor site from peripheral blood (V82) and may exert anti-tumor activity; however, with tumor progression, factors produced in the microenvironment cause polarization of $\gamma \delta$ cells from $\gamma \delta 1$ to $\gamma \delta 17$ and $\gamma \delta$ reg, which instead promote tumor progression. A plethora of cell types present in the tumor microenvironment may actually provide the source of such $\gamma \delta$ cells polarizing factors.

For instance, colon cancer stem cells and tumor-associated macrophages and fibroblasts produce huge amounts of TGF- $\beta$ (72) which, in combination with other cytokines present in the microenvironment, contributes to polarization of $\gamma \delta \mathrm{T}$ cells to $\gamma \delta 17$ and $\gamma \delta$ reg.
Macrophages, DCs, and other myeloid cells, which are typically found in the solid tumor microenvironment, produce IL-15, which in combination with TGF- $\beta$ determines $\gamma \delta$ reg polarization (26), and IL- $1 \beta$, IL-6, IL-23, and TGF- $\beta$, which in different combination promote $\gamma \delta 17$ Polarization (22).

Finally, it is also possible that those $\gamma \delta \mathrm{T}$ cells within TILs equipped with anti-tumor activities die after antigenic activation and the frequencies of $\gamma \delta$ reg, which would be less tumor reactive or resistant to cell death then increase. Moreover, nitric oxide, which is largely produced by MDSC in the tumor microenvironment may contribute to apoptosis of $\gamma \delta$ T cells induced by antigen activation (73).

Once activated, $\gamma \delta$ reg and $\gamma \delta 17$ amplify the immunoregulatory process in different ways (Figure 2): IL-17 promotes VEGF production by cancer cells and macrophages, and CXCL5 production by tumor cells which, in turn, recruited MDSC. An activatory cross-talk is then established at the tumor site between MDSC and $\gamma \delta 17$, by which IL-17 induces IL- $1 \beta$ and IL-23 production by MDSC and these cytokines promote further differentiation and activation of $\gamma \delta 17 \mathrm{~T}$ cells. Finally, $\gamma \delta$ reg produce IL-10 and TGF- $\beta$, which act on several cellular targets to promote immunosuppression at the tumor site and favor tumor progression.

Several recent discoveries have been made toward understanding the biological effects of cytokines, particularly TGF$\beta$, produced in the tumor microenvironment that can polarize many arms of the immune system. Thus, and similarly to what we propose to occur for $\gamma \delta$ cells, cytokines present in the tumor microenvironment induce DCs to acquire a tolerogenic

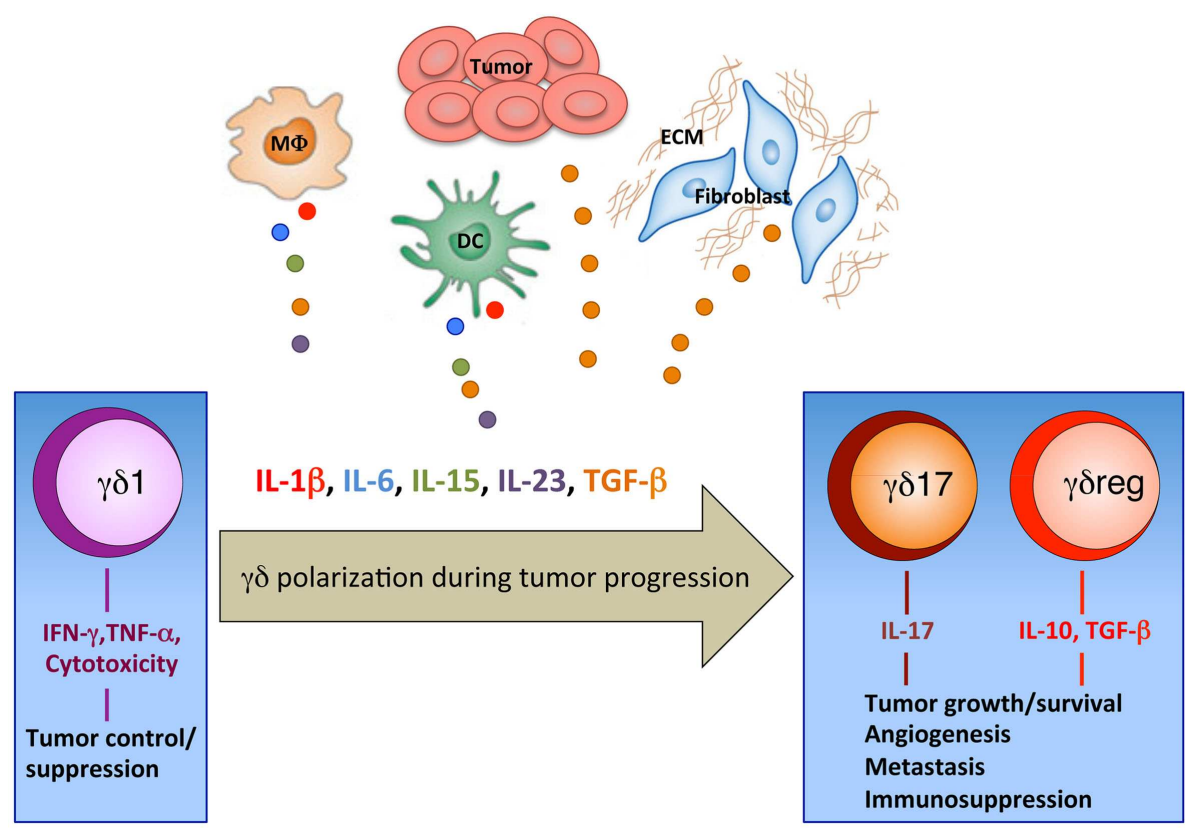

FIGURE 1 | Polarization of $\gamma \delta$ T cells in the tumor microenvironment. Our working hypothesis for the recruitment of $\gamma \delta$ T cells with different phenotypes and functions into the tumor site. At early stages of tumor development tumor cells produce chemokines, which recruit $\gamma \delta$ T cells of the $\gamma \delta 1$ type equipped with anti-tumor activities (IFN- $\gamma$ and TNF- $\alpha$ production and cytotoxic potential). It is speculated that during progression, tumors have denser stroma (ECM, extracellular matrix) and alternative DCs, myeloid, or macrophage $(M \Phi)$ populations, which produce cytokines that accumulate in the tumor microenvironment and cause polarization of $\gamma \delta$ cells from $\gamma \delta 1$ to $\gamma \delta 17$ and $\gamma \delta$ reg. 


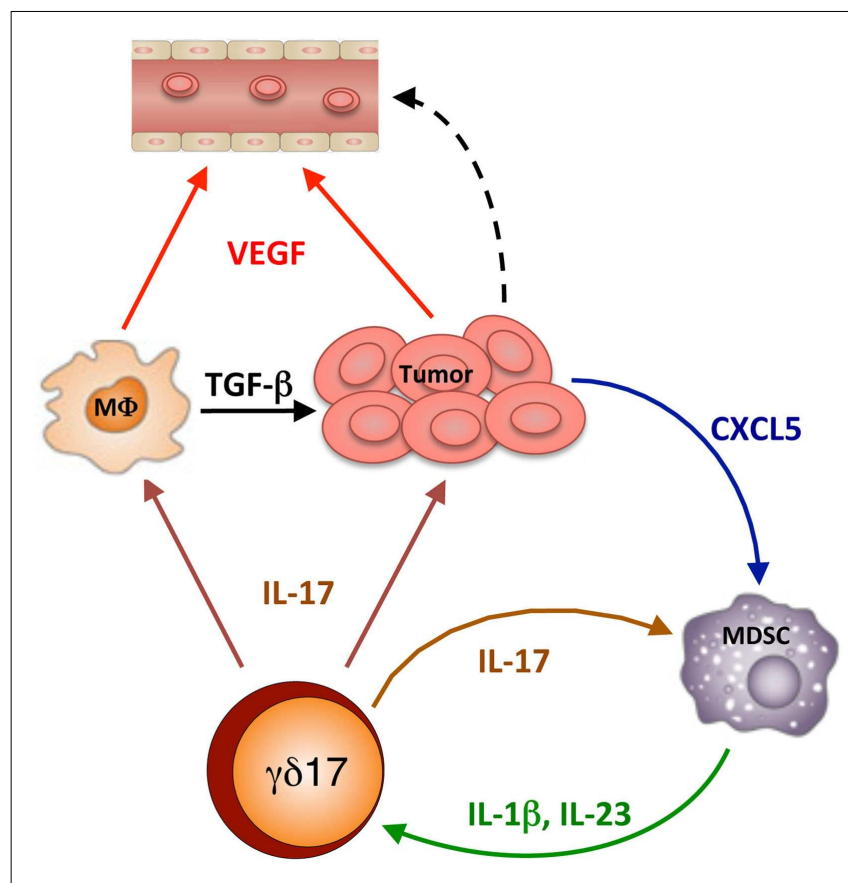

FIGURE 2 | IL-17-dependent cellular interactions into the tumor microenvironment. $\gamma \delta 17$ release $\mathrm{IL}-17$, which mediates several effects: it promotes VEGF production by cancer cells and macrophages, thus causing tumor vascularization and favoring metastasis; it promotes TGF- $\beta$ production by macrophages (M $\Phi$ ) thus causing tumor growth; it promotes CXCL5 production by tumor cells which, in turn, recruited MDSC. Then a mutual stimulatory circuit is established between MDSC and $\gamma \delta 17$, which involves IL-17, IL-1 $\beta$, and IL-23, which leads to further differentiation and activation of $\gamma \delta 17 \mathrm{~T}$ cells and amplification of the immunosuppressive process.

phenotype, convert N1 neutrophils to a N2 phenotype and promote the recruitment of M2 over M1 macrophages. Within the tumor microenvironment, cytokines also inhibit Th1 and CD8 CTL functions and probably promote a shift toward Th2, Th17, and Tc17 differentiation and convert CD4 effector $\mathrm{T}$ cells to induced Treg (iTReg) cells. For a systematic review on the polarization of immune cells in the tumor microenvironment see in Ref. (74).

\section{CONCLUSION AND PERSPECTIVES}

The mutual and interdependent interaction between tumor and its microenvironment is a crucial topic in cancer research and therapy, as recently demonstrated by the finding that targeting stromal factors could improve efficacies of current therapeutics and prevent metastasis. For instance, combinatorial therapy with an agonistic mAb against CD40 and standard gemcitabine chemotherapy, proved unexpectedly efficient in pancreatic cancer (75). In this system, the anti-CD40 mAb caused massive recruitment of macrophages at the tumor site, which caused severe disruption of the tumor stroma thus allowing increased concentrations of gemcitabine to accumulate to the tumor site (75). Similarly, the identification of defined immunosuppressive pathways in the tumor microenvironment has pointed toward therapeutic targets that are amenable to clinical intervention: these include, for instance, mAbs to PD-1 or PD-L, CTLA-4, CD25, and small-molecule inhibitors that block IDO enzymatic activity [reviewed in Ref. (76)]. These novel strategies must be kept in mind when designing $\gamma \delta \mathrm{T}$ cell-based therapy. Moreover radiation therapy, low dose traditional chemotherapeutic drugs and aminobisphosphonates not only sensitize tumor cells to immune recognition and killing, but also modulate the tumor microenvironment and contribute to the therapeutic effect (77-80): for instance, zoledronic acid at clinically achievable doses repolarizes tumor-associated macrophages to a $\mathrm{M} 1$ phenotype and reduces the number of MDSC (81).

$\gamma \delta \mathrm{T}$ cell-based immunotherapy is emerging to be a powerful treatment option for patients with different types of tumors. It includes the in vivo activation of $\gamma \delta$ cells or the adoptive transfer of ex vivo-expanded $\gamma \delta$ cells. Although we have no evidence of the fate of the activated $\gamma \delta$ cells and the long term effects of the $\gamma \delta$ cell-based therapies in preclinical and clinical studies, it is reasonable to predict that the tumor microenvironment plays an indispensable role in limiting the effectiveness of $\gamma \delta \mathrm{T}$ cell-based immunotherapies. Additionally, the local expansion of adoptively transferred $\gamma \delta \mathrm{T}$ cells has to be increased to achieve higher $\mathrm{T}$ cell numbers at the tumor site.

Therefore, combination regimens consisting of $\gamma \delta$ T cell-based therapies and strategies aimed to circumvent the negative impact of the tumor microenvironment onto $\gamma \delta$ T cells and induce $\gamma \delta$ $\mathrm{T}$ cell repolarization, may prove efficacious and achieve clinical benefit in patients with different types of tumor.

\section{ACKNOWLEDGMENTS}

This work was supported by grants from the Ministry of Health "Ricerca Finalizzata 2007" (to Franceso Dieli) and the University of Palermo. Elena Lo Presti is a student of the International Ph.D. Program in Immunopharmacology at the University of Palermo.

\section{REFERENCES}

1. Hayday AC. $\gamma \delta$ T cells: a right time and a right place for a conserved third way of protection. Annu Rev Immunol (2000) 18:975-1026. doi:10.1146/annurev. immunol.18.1.975

2. Bonneville M, O’Brien RL, Born WK. $\gamma \delta$ T cell effector functions: a blend of innate programming and acquired plasticity. Nat Rev Immunol (2010) 10:467-78. doi:10.1038/nri2781

3. Groh V, Steinle A, Bauer S, Spies T. Recognition of stress-induced MHC molecules by intestinal epithelial $\gamma \delta \mathrm{T}$ cells. Science (1998) 279:1737-40. doi:10.1126/science.279.5357.1737

4. Poggi A, Venturino C, Catellani S, Clavio M, Miglino M, Gobbi M, et al. V $\delta 1$ T lymphocytes from B-CLL patients recognize ULBP3 expressed on leukemic B cells and up-regulated by trans-retinoic acid. Cancer Res (2004) 64:9172-9. doi:10.1158/0008-5472.CAN-04-2417

5. Tanaka Y, Morita CT, Tanaka Y, Nieves E, Brenner MB, Bloom BR. Natural and synthetic non-peptide antigens recognized by human $\gamma \delta$ T cells. Nature (1995) 75:155-8. doi:10.1038/375155a0

6. Eberl M, Hintz M, Reichenberg A, Kollas AK, Wiesner J, Jomaa H. Microbial isoprenoid biosynthesis and human $\gamma \delta$ T cell activation. FEBS Lett (2003) 544:4-10. doi:10.1016/S0014-5793(03)00483-6

7. Sireci G, Espinosa E, Di Sano C, Dieli F, Fournié JJ, Salerno A. Differential activation of human $\gamma \delta$ cells by nonpeptide phosphoantigens. Eur J Immunol (2001) 31:1628-35. doi:10.1002/1521-4141(200105)31:5<1628::AIDIMMU1628>3.0.CO;2-T

8. Vantourout P, Hayday A. Six-of-the-best: unique contributions of $\gamma \delta \mathrm{T}$ cells to immunology. Nat Rev Immunol (2013) 13:88-100. doi:10.1038/nri3384

9. Scotet E, Martinez LO, Grant E, Barbaras R, Jeno P, Guiraud M, et al. Tumor recognition following $\mathrm{V} \gamma 9 \mathrm{~V} \delta 2 \mathrm{~T}$ cell receptor interactions with a 
surface F1-ATPase-related structure and apolipoprotein A-I. Immunity (2005) 22:71-80. doi:10.1016/j.immuni.2004.11.012

10. Vavassori S, Kumar A, Wan GS, Ramanjaneyulu GS, Cavallari M, El Daker S, et al. Butyrophilin 3A1 binds phosphorylated antigens and stimulates human $\gamma \delta$ T cells. Nat Immunol (2013) 14:908-16. doi:10.1038/ni.2665

11. Harly C, Guillaume Y, Nedellec S, Peigné CM, Mönkkönen H, Mönkkönen J, et al. Key implication of CD277/butyrophilin-3 (BTN3A) in cellular stress sensing by a major human $\gamma \delta$ T-cell subset. Blood (2012) 120:2269-79. doi:10.1182/blood-2012-05-430470

12. Sandstrom A, Peigné CM, Léger A, Crooks JE, Konczak F, Gesnel MC, et al. The intracellular B30.2 domain of butyrophilin 3A1 binds phosphoantigens to mediate activation of human $\mathrm{V} \gamma 9 \mathrm{~V} \delta 2 \mathrm{~T}$ cells. Immunity (2014) 40:490-500. doi:10.1016/j.immuni.2014.03.003

13. Roelofs AJ, Jauhiainen M, Monkkonen H, Rogers MJ, Monkkonen J, Thompson K. Peripheral blood monocytes are responsible for $\gamma \delta \mathrm{T}$ cell activation induced by zoledronic acid through accumulation of IPP/DMAPP. Br J Haematol (2009) 144:245-50. doi:10.1111/j.1365-2141.2008.07435.x

14. Li J, Herold MJ, Kimmel B, Muller I, Rincon-Orozco B, Kunzmann V, et al. Reduced expression of the mevalonate pathway enzyme farnesyl pyrophosphate synthase unveils recognition of tumor cells by $\mathrm{V} \gamma 9 \mathrm{~V} \delta 2 \mathrm{~T}$ cells. J Immunol (2009) 182:8118-24. doi:10.4049/jimmunol.0900101

15. Gober HJ, Kistowska M, Angman L, Jeno P, Mori L, De Libero G. Human T cell receptor $\gamma \delta \mathrm{T}$ cells recognize endogenous mevalonate metabolites in tumor cells. J Exp Med (2003) 197:163-8. doi:10.1084/jem.20021500

16. Dieli F, Poccia F, Lipp M, Sireci G, Caccamo N, Di Sano C, et al. Differentiation of effector/memory V $\delta 2 \mathrm{~T}$ cells and migratory routes in lymph nodes or inflammatory sites. J Exp Med (2003) 198:391-7. doi:10.1084/jem. 20030235

17. Caccamo N, Meraviglia S, Ferlazzo V, Angelini D, Borsellino G, Poccia F, et al. Differential requirements for antigen or homeostatic cytokines for proliferation and differentiation of human $\mathrm{V} \gamma 9 \mathrm{~V} \delta 2$ naive, memory and effector $\mathrm{T}$ cell subsets. Eur J Immunol (2005) 35:1764-72. doi:10.1002/eji.200525983

18. Caccamo N, Todaro M, Sireci G, Meraviglia S, Stassi G, Dieli F. Mechanisms underlying lineage commitment and plasticity of human $\gamma \delta \mathrm{T}$ cells. Cell Mol Immunol (2013) 10:30-4. doi:10.1038/cmi.2012.42

19. Sireci G, Champagne E, Fournié JJ, Dieli F, Salerno A. Patterns of phosphoantigen stimulation of human $\mathrm{V} \gamma 9 \mathrm{~V} \delta 2 \mathrm{~T}$ cell clones include Th0 cytokines. Hum Immunol (1997) 58:70-82. doi:10.1016/S0198-8859(97)00211-5

20. Wesch D, Glatzel A, Kabelitz D. Differentiation of resting human peripheral blood $\gamma \delta \mathrm{T}$ cells toward Th1- or Th2-phenotype. Cell Immunol (2001) 212:110-7.

21. Ness-Schwickerath KJ, Jin C, Morita CT. Cytokine requirements for the differentiation and expansion of IL-17A- and IL-22-producing human $\mathrm{V} \gamma 9 \mathrm{~V} \delta 2 \mathrm{~T}$ cells. J Immunol (2010) 184:7268-80. doi:10.4049/jimmunol.1000600

22. Caccamo N, La Mendola C, Orlando V, Meraviglia S, Todaro M, Stassi G, et al. Differentiation, phenotype and function of interleukin-17-producing human V $\gamma 9$ V 82 T cells. Blood (2011) 118:129-38. doi:10.1182/blood-2011-01-331298

23. Fenoglio D, Poggi A, Catellani S, Battaglia F, Ferrera A, Setti M, et al. V $\delta 1$ T lymphocytes producing IFN- $\gamma$ and IL-17 are expanded in HIV-1-infected patients and respond to Candida albicans. Blood (2009) 113:6611-8. doi:10.1182/blood2009-01-198028

24. Bansal RR, Mackay CR, Moser B, Eberl M. IL-21 enhances the potential of human $\gamma \delta$ T cells to provide B-cell help. Eur J Immunol (2012) 42:110-9. doi:10.1002/eji.201142017

25. Caccamo N, Todaro M, La Manna MP, Sireci G, Stassi G, Dieli F. IL-21 regulates the differentiation of a human $\gamma \delta$ T cell subset equipped with B cell helper activity. PLoS One (2012) 7:e41940. doi:10.1371/journal.pone.0041940

26. Casetti R, Agrati C, Wallace M, Sacchi A, Martini F, Martino A, et al. TGF- $\beta 1$ and IL-15 Induce FOXP $3^{+} \gamma \delta$ regulatory T cells in the presence of antigen stimulation. J Immunol (2009) 183:3574-7. doi:10.4049/jimmunol.0901334

27. Smyth MJ, Dunn GP, Schreiber RD. Cancer immunosurveillance and immunoediting: the roles of immunity in suppressing tumor development and shaping tumor immunogenicity. Adv Immunol (2006) 90:1-50. doi:10.1016/S00652776(06)90001-7

28. Gattinoni L, Powell DJ Jr, Rosenberg SA, Restifo NP. Adoptive immunotherapy for cancer: building on success. Nat Rev Immunol (2006) 6:383-93. doi:10.1038/nri1842
29. Kunzmann V, Bauer E, Feurle J, Weihinger F, Torny HP, Wilhelm M. Stimulation of $\gamma \delta \mathrm{T}$ cells by aminobisphosphonates and induction of anti plasma cell activity in multiple myeloma. Blood (2000) 86:384-92.

30. Corvaisier M, Moreau-Aubry A, Diez E, Bennouna J, Mosnier JF, Scotet E, et al. $\mathrm{V} \gamma 9 \mathrm{~V} \delta 2 \mathrm{~T}$ cell response to colon carcinoma cells. J Immunol (2005) 175:5481-8. doi:10.4049/jimmunol.175.8.5481

31. Belmant C, Decise D, Fournie JJ. Phosphoantigens and aminobisphosphonates: new leads targeting $\gamma \delta \mathrm{T}$ lymphocytes for cancer immunotherapy. Drug Discov Today Ther Strateg (2006) 3:17-23. doi:10.1016/j.ddstr.2006.02.001

32. Liu Z, Guo BL, Gehrs BC, Nan L, Lopez RD. Ex vivo expanded human V $\gamma 9 \mathrm{~V} \delta 2$ $\gamma \delta^{+} \mathrm{T}$ cells mediate innate antitumor activity against human prostate cancer cells in vitro. J Urol (2005) 173:1552-6. doi:10.1097/01.ju.0000154355.45816.0b

33. Viey E, Fromont G, Escudier B, Morel Y, Da Rocha S, Chouaib S, et al. Phosphostim activated $\gamma \delta \mathrm{T}$ cells kill autologous metastatic renal cell carcinoma. $J$ Immunol (2005) 174:1338-47. doi:10.4049/jimmunol.174.3.1338

34. Kabelitz D, Wesch D, Pitters E, Zoller M. Characterization of tumor reactivity of human $\mathrm{V} \gamma 9 \mathrm{~V} \delta 2 \gamma \delta \mathrm{T}$ cells in vitro and in SCID mice in vivo. J Immunol (2004) 173:6767-76. doi:10.4049/jimmunol.173.11.6767

35. D’Asaro M, La Mendola C, Di Liberto D, Orlando V, Todaro M, Spina M, et al. $\mathrm{V} \gamma 9 \mathrm{~V} \delta 2 \mathrm{~T}$ lymphocytes efficiently recognize and kill zoledronate-sensitized, imatinib-sensitive, and imatinib-resistant chronic myelogenous leukemia cells. J Immunol (2010) 184:3260-8. doi:10.4049/jimmunol.0903454

36. Harwood HJ Jr, Alvarez IM, Noyes WD, Stacpoole PW. In vivo regulation of human leukocyte 3-hydroxy-3-methylglutaryl coenzyme A reductase: increased enzyme protein concentration and catalytic efficiency in human leukemia and lymphoma. J Lipid Res (1991) 32:1237-52.

37. Kunzmann V, Bauer E, Wilhelm M. $\gamma \delta$ T-cell stimulation by pamidronate. $N$ Engl J Med (1999) 340:737-8. doi:10.1056/NEJM199903043400914

38. Girlanda S, Fortis C, Belloni D, Ferrero E, Ticozzi P, Sciorati C, et al. MICA expressed by multiple myeloma and monoclonal gammopathy of undetermined significance plasma cells co-stimulates pamidronate-activated $\gamma \delta$ lymphocytes. Cancer Res (2005) 65:7502-8. doi:10.1158/0008-5472.CAN-05-0731

39. Dieli F, Gebbia N, Poccia F, Caccamo N, Montesano C, Fulfaro F, et al. Induction of $\gamma \delta$ T-lymphocyte effector functions by bisphosphonate zoledronic acid in cancer patients in vivo. Blood (2003) 102:2310-1. doi:10.1182/blood-2003-05-1655

40. Das H, Groh V, Kuijl C, Sugita M, Morita CT, Spies T, et al. MICA engagement by human $\mathrm{V} \gamma 9 \mathrm{~V} \delta 2 \mathrm{~T}$ cells enhances their antigen dependent effector function. Immunity (2001) 15:83-93. doi:10.1016/S1074-7613(01)00168-6

41. Rincon-Orozco B, Kunzmann V, Wrobel P, Kabelitz D, Steinle A, Herrmann T. Activation of $\mathrm{V} \gamma 9 \mathrm{~V} \delta 2 \mathrm{~T}$ cells by NKG2D. J Immunol (2005) 175:2144-51. doi:10.4049/jimmunol.175.4.2144

42. Lanca T, Correia DV, Moita CF, Raquel H, Neves-Costa A, Ferreira C, et al. The MHC class Ib protein ULBP1 is a nonredundant determinant of leukemia/lymphoma susceptibility to $\gamma \delta$ T-cell cytotoxicity. Blood (2010) 115:2407-11. doi:10.1182/blood-2009-08-237123

43. Gomes AQ, Correia DV, Grosso AR, Lança T, Ferreira C, Lacerda JF, et al. Identification of a panel of ten cell surface protein antigens associated with immunotargeting of leukemias and lymphomas by peripheral blood $\gamma \delta \mathrm{T}$ cells. Haematologica (2010) 95:1397-404. doi:10.3324/haematol.2009.020602

44. Dieli F, Troye-Blomberg M, Ivanyi J, Fournie M, Bonneville MA, Peyrat G, et al. Granulysin dependent killing of intracellular and extracellular Mycobacterium tuberculosis by V $\gamma 9 \mathrm{~V} \delta 2 \mathrm{~T}$ lymphocytes. J Infect Dis (2001) 184:1082-5. doi: $10.1086 / 323600$

45. Vermijlen D, Ellis P, Langford C, Klein A, Engel R, Willimann K, et al. Distinct cytokine driven responses of activated blood $\gamma \delta \mathrm{T}$ cells: insights into unconventional T cell pleiotropy. J Immunol (2007) 178:4304-14. doi:10.4049/jimmunol. 178.7.4304

46. Dalton JE, Howell G, Pearson J, Scott P, Carding SR. Fas-Fas ligand interactions are essential for the binding to and killing of activated macrophages by $\gamma \delta$. $J$ Immunol (2004) 173:3660-7. doi:10.4049/jimmunol.173.6.3660

47. Ismaili J, Olislagers V, Poupot R, Fournie JJ, Goldman M. Human $\gamma \delta \mathrm{T}$ cells induce dendritic cell maturation. Clin Immunol (2002) 103:296-302. doi: $10.1006 /$ clim.2002.5218

48. Conti L, Casetti R, Cardone M, Varano B, Martino A, Belardelli F, et al. Reciprocal activating interaction between dendritic cells and pamidronate-stimulated $\gamma \delta \mathrm{T}$ cells: role of CD86 and inflammatory cytokines. J Immunol (2005) 174:252-60. doi:10.4049/jimmunol.174.1.252 
49. Devilder MC, Maillet S, Bouyge-Moreau I, Donnadieu E, Bonneville M, Scotet E. Potentiation of antigen-stimulated $\mathrm{V} \gamma 9 \mathrm{~V} \delta 2 \mathrm{~T}$ cell cytokine production by immature dendritic cells (DC) and reciprocal effect on DC maturation. J Immunol (2006) 176:1386-93. doi:10.4049/jimmunol.176.3.1386

50. Buccheri S, Guggino G, Caccamo N, Li Donni P, Dieli F. Efficacy and safety of $\gamma \delta$ T cell-based tumor immunotherapy: a meta-analysis. J Biol Regul Homeost Agents (2014) 28:81-90.

51. Gooden MJ, de Bock GH, Leffers N, Daemen T, Nijman HW. The prognostic influence of tumour-infiltrating lymphocytes in cancer: a systematic review with meta-analysis. Br J Cancer (2011) 105:93-103. doi:10.1038/bjc.2011.189

52. Sasada T, Suekane S. Variation of tumor-infiltrating lymphocytes in human cancers: controversy on clinical significance. Immunotherapy (2011) 3:1235-51. doi:10.2217/imt.11.106

53. Bialasiewicz AA, Ma JX, Richard G. $\alpha \beta$ - and $\gamma \delta \mathrm{TCR}^{+}$lymphocyte infiltration in necrotising choroidal melanomas. Br J Ophthalmol (1999) 83:1069-73. doi:10.1136/bjo.83.9.1069

54. Inman BA, Frigola X, Harris KJ, Kuntz SM, Lohse CM, Leibovich BC, et al. Questionable relevance of $\gamma \delta \mathrm{T}$ lymphocytes in renal cell carcinoma. J Immunol (2008) 180:3578-84. doi:10.4049/jimmunol.180.5.3578

55. Ma C, Zhang Q, Ye J, Wang F, Zhang Y, Wevers E, et al. Tumor-infiltrating $\gamma \delta \mathrm{T}$ lymphocytes predict clinical outcome in human breast cancer. JImmunol (2012) 189:5029-36. doi:10.4049/jimmunol.1201892

56. Cordova A, Toia F, La Mendola C, Orlando V, Meraviglia S, Rinaldi G, et al. Characterization of human $\gamma \delta \mathrm{T}$ lymphocytes infiltrating primary malignant melanomas. PLoS One (2012) 7:e49878. doi:10.1371/journal.pone.0049878

57. Wu P, Wu D, Ni C, Ye J, Chen W, Hu G, et al. $\gamma \delta$ T17 cells promote the accumulation and expansion of myeloid-derived suppressor cells in human colorectal cancer. Immunity (2014) 40:785-800. doi:10.1016/j.immuni.2014.03.013

58. Groh V, Rhinehart R, Secrist H, Bauer S, Grabstein KH, Spies T. Broad tumorassociated expression and recognition by tumor-derived $\gamma \delta$ T cells of MICA and MICB. Proc Natl Acad Sci US A (1999) 96:6879-84. doi:10.1073/pnas.96.12.6879

59. Chen J, Niu H, He W, Ba D. Antitumor activity of expanded human tumorinfiltrating $\gamma \delta$ T lymphocytes. Int Arch Allergy Immunol (2001) 125:256-63. doi: $10.1159 / 000053824$

60. Choudhary A, Davodeau F, Moreau A, Peyrat MA, Bonneville M, Jotereau F. Selective lysis of autologous tumor cells by recurrent $\gamma \delta$ tumor-infiltrating lymphocytes from renal carcinoma. J Immunol (1995) 154:3932-40.

61. Ferrarini M, Heltai S, Pupa SM, Mernard S, Zocchi R. Killing of laminin receptorpositive human lung cancers by tumor infiltrating lymphocytes bearing $\gamma \delta^{+}$ T-cell receptors. J Natl Cancer Inst (1996) 88:436-41. doi:10.1093/jnci/88.7.436

62. Maeurer MJ, Martin D, Walter W, Liu K, Zitvogel L, Halusczcak K, et al. Human intestinal $\mathrm{V} \delta 1^{+}$lymphocytes recognize tumor cells of epithelial origin. J Exp Med (1996) 183:1681-96. doi:10.1084/jem.183.4.1681

63. Kitayama J, Atomi Y, Nagawa H, Kuroda A, Mutoh T, Minami M, et al. Functional analysis of TCR $\gamma \delta^{+}$T cells in tumour-infiltrating lymphocytes (TIL) of human pancreatic cancer. Clin Exp Immunol (1993) 93:442-7. doi:10.1111/j. 1365-2249.1993.tb08198.x

64. Peng G, Wang HY, Peng W, Kiniwa Y, Seo KH, Wang RF. Tumor-infiltrating $\gamma \delta \mathrm{T}$ cells suppress $\mathrm{T}$ and dendritic cell function via mechanisms controlled by a unique toll-like receptor signaling pathway. Immunity (2007) 27:334-48. doi:10.1016/j.immuni.2007.05.020

65. Ye J, Ma C, Hsueh EC, Eickhoff CS, Zhang Y, Varvares MA, et al. Tumorderived $\gamma \delta$ regulatory $\mathrm{T}$ cells suppress innate and adaptive immunity through the induction of immunosenescence. J Immunol (2013) 190:2403-14. doi:10. 4049/jimmunol.1202369

66. Wakita D, Sumida K, Iwakura Y, Nishikawa H, Ohkuri T, Chamoto K, et al. Tumor-infiltrating IL-17-producing $\gamma \delta \mathrm{T}$ cells support the progression of tumor by promoting angiogenesis. Eur J Immunol (2010) 40:1927-37. doi:10.1002/eji. 200940157

67. Ma S, Cheng Q, Cai Y, Gong H, Wu Y, Yu X, et al. IL-17A produced by $\gamma \delta \mathrm{T}$ cells promotes tumor growth in hepatocellular carcinoma. Cancer Res (2014) 74:1969-82. doi:10.1158/0008-5472.CAN-13-2534

68. Rei M, Gonçalves-Sousa N, Lança T, Thompson RG, Mensurado S, Balkwill FR, et al. Murine CD27- $\mathrm{V} \gamma 6^{+} \gamma \delta \mathrm{T}$ cells producing IL-17A promote ovarian cancer growth via mobilization of protumor small peritoneal macrophages. Proc Natl Acad Sci U S A (2014) 111:E3562-70. doi:10.1073/pnas.1403424111

69. Burdelya L, Kujawski M, Niu G, Zhong B, Wang T, Zhang S, et al. STAT3 activity in melanoma cells affects migration of immune effector cells and nitric oxide-mediated antitumor effects. J Immunol (2005) 174:3925-31. doi:10.4049/ jimmunol.174.7.3925

70. Ugurel S, Schrama D, Keller G, Schadendorf D, Bröcker EB, Houben R, et al. Impact of the CCR5 gene polymorphism on the survival of metastatic melanoma patients receiving immunotherapy. Cancer Immunol Immunother (2008) 57:685-91. doi:10.1007/s00262-007-0407-z

71. Catalano V, Turdo A, Di Franco S, Dieli F, Todaro M, Stassi G. Tumor and its microenvironment: a synergistic interplay. Semin Cancer Biol (2013) 23:522-32. doi:10.1016/j.semcancer.2013.08.007

72. Todaro M, Gaggianesi M, Catalano V, Benfante A, Iovino F, Biffoni M, et al. $\mathrm{CD} 44 \mathrm{v} 6$ is a marker of constitutive and reprogrammed cancer stem cells driving colon cancer metastasis. Cell Stem Cell (2014) 14:342-56. doi:10.1016/j.stem. 2014.01.009

73. Atre N, Thomas L, Mistry R, Pathak K, Chiplunkar S. Role of nitric oxide in heat shock protein induced apoptosis of gammadeltaT cells. Int J Cancer (2006) 119:1368-76. doi:10.1002/ijc.21966

74. Flavell RA, Sanjabi S, Wrzesinski SH, Licona-Limón P. The polarization of immune cells in the tumour environment by TGF $\beta$. Nat Rev Immunol (2010) 10:554-67. doi:10.1038/nri2808

75. Beatty GL, Chiorean EG, Fishman MP, Saboury B, Teitelbaum UR, Sun W, et al. CD40 agonists alter tumor stroma and show efficacy against pancreatic carcinoma in mice and humans. Science (2011) 331:1612-6. doi:10.1126/science. 1198443

76. Gajewski TF, Schreiber H, Fu YX. Innate and adaptive immune cells in the tumor microenvironment. Nat Immunol (2013) 14:1014-22. doi:10.1038/ni.2703

77. Burnette B, Fu YX, Weichselbaum RR. The confluence of radiotherapy and immunotherapy. Front Oncol (2012) 2:143. doi:10.3389/fonc.2012.00143

78. Todaro M, Meraviglia S, Caccamo N, Stassi G, Dieli F. Combining conventional chemotherapy and $\gamma \delta \mathrm{T}$ cell-based immunotherapy to target cancer-initiating cells. Oncoimmunology (2013) 2:e25821. doi:10.4161/onci.25821

79. Todaro M, D’Asaro M, Caccamo N, Iovino F, Francipane MG, Meraviglia S, et al. Efficient killing of human colon cancer stem cells by $\gamma \delta$ T lymphocytes. $J$ Immunol (2009) 182:7287-96. doi:10.4049/jimmunol.0804288

80. Santolaria T, Robard M, Léger A, Catros V, Bonneville M, Scotet E. Repeated systemic administrations of both aminobisphosphonates and human $\mathrm{V} \gamma 9 \mathrm{~V} \delta 2$ $\mathrm{T}$ cells efficiently control tumor development in vivo. J Immunol (2013) 191:1993-2000. doi:10.4049/jimmunol.1300255

81. Coscia M, Quaglino E, Iezzi M, Curcio C, Pantaleoni F, Riganti C, et al. Zoledronic acid repolarizes tumor-associated macrophages and inhibits mammary carcinogenesis by targeting the mevalonate pathway. J Cell Mol Med (2010) 14:2803-15. doi:10.1111/j.1582-4934.2009.00926.x

Conflict of Interest Statement: The authors declare that the research was conducted in the absence of any commercial or financial relationships that could be construed as a potential conflict of interest.

Received: 14 October 2014; paper pending published: 05 November 2014; accepted: 12 November 2014; published online: 24 November 2014.

Citation: Lo Presti E, Dieli F and Meraviglia S (2014) Tumor-infiltrating $\gamma \delta T$ Tymphocytes: pathogenic role, clinical significance, and differential programing in the tumor microenvironment. Front. Immunol. 5:607. doi: 10.3389/fimmu.2014.00607

This article was submitted to T Cell Biology, a section of the journal Frontiers in Immunology.

Copyright (C) 2014 Lo Presti, Dieli and Meraviglia. This is an open-access article distributed under the terms of the Creative Commons Attribution License (CC BY). The use, distribution or reproduction in other forums is permitted, provided the original author(s) or licensor are credited and that the original publication in this journal is cited, in accordance with accepted academic practice. No use, distribution or reproduction is permitted which does not comply with these terms. 